\title{
Challenge with a Personal Cascade Impactor Sampler in a Silicon Metal Smelter
}

Aerosol and Air Quality Research

\section{OPEN ACCESS}

Received: October 14, 2020

Revised: January 15, 2021

Accepted: January 17, 2021

${ }^{*}$ Corresponding Author:

torunn.ervik@stami.no

\section{Publisher:}

Taiwan Association for Aerosol Research

ISSN: $1680-8584$ print

ISSN: 2071-1409 online

Copyright: The Author(s). This is an open access article distributed under the terms of the Creative Commons Attribution License (CC BY 4.0), which permits unrestricted use, distribution, and reproduction in any medium, provided the original author and source are cited.

\author{
Balázs Berlinger ${ }^{1,2}$, Torunn K. Ervik ${ }^{1 *}$, Konrad Kandler ${ }^{3}$, Bente Ulvestad ${ }^{4}$, \\ Nathalie Benker ${ }^{3}$, Dag G. Ellingsen ${ }^{1}$, Merete D. Bugge ${ }^{4}$ \\ ${ }^{1}$ Chemical Work Environment, National Institute of Occupational Health, Pb 5330 Majorstuen, \\ 0304 Oslo, Norway \\ ${ }^{2}$ Soos Research and Development Center, University of Pannonia, Zrinyi Miklos str. 18, 8800 \\ Nagykanizsa, Hungary \\ ${ }^{3}$ Institut für Angewandte Geowissenschaften, Technische Universität Darmstadt, \\ Schnittspahnstr. 9, 64287 Darmstadt, Germany \\ ${ }^{4}$ Occupational Medicine and Epidemiology, National Institute of Occupational Health, $\mathrm{Pb} 5330$ \\ Majorstuen, 0304 Oslo, Norway
}

\section{ABSTRACT}

Cascade impactors are useful tools in the measurement of particle size mass distribution of workplace aerosols. The application of cascade impactors, however, is sometimes challenging. Personal aerosol samples were collected by Sioutas cascade impactors and respirable cyclones in parallel in a silicon (Si) metal smelter to investigate the different particulate matter (PM) fractions. In a second campaign, nine new air samples were collected with the Sioutas personal cascade impactors using stationary sampling. It was found that wall deposition was substantial in the upper stages of the Sioutas cascade impactors, which meant that quite often more PM was deposited on the inner walls of the impactor than on the filter substrates. At the same time, wall deposition did most probably not affect the collection of the finest particles $(<0.25 \mu \mathrm{m})$. Besides wall deposition of the particles, the effect of high PM concentration on the impactor performance, particle bouncing and blow off, high particle mass loading and impact fragmentation of the particle agglomerates were considered for explaining the malfunctioning of the Sioutas impactors in the Si metal smelter. Furthermore, concentrations of the finest PM fraction $(<0.25 \mu \mathrm{m})$ and respirable fraction both collected by personal sampling are reported and discussed in the paper.

Keywords: Ultrafine particles, Respirable fraction, Sioutas cascade impactor, Wall deposition

\section{INTRODUCTION}

The health effects in the respiratory tract resulting from the inhaled and deposited particulate matter (PM) depend on the dose received, the site of deposition and the body's response to the deposited particles (Volkwein et al., 2011). Consequently, an important aim of workplace air measurement is to estimate the effective dose of PM delivered to the lungs. Aerosol particle size is one of the key factors that determine where and whether particles will deposit in the respiratory tract (ICRP, 1994; Bartley and Vincent, 2011).

From most conventional workplace aerosol measurements information on particle size distribution is not available. Cascade impactors can be useful tools to assess the mass size distribution. In spite of the importance of the particle size distribution in workplace aerosol characterisation, cascade impactors are not very widespread for personal sampling. Nevertheless, there exist a few alternatives and an overview of published studies follows. Nieuwenhuijsen et al. (1998) applied Sierra Marple 294 cascade impactors to measure personal dust exposure levels and the particle size distribution of the dust occurring during various agricultural operations in California. Cohen and Powers (2000) investigated the exposure to copper and zinc in a nonferrous foundry. 
Results from single jet personal cascade impactors with five to six stages were compared to previous findings obtained by using cyclones. In a study by Chen et al. (2007) particle size distributions of oil mists in fastener manufacturing industry were determined by modified Marple 8-stage cascade impactors. Dufresne et al. (2009) applied 8-stage Sierra impactors in a magnesium foundry and three aluminium smelters. The collected samples were used to determine the beryllium content in the different size fractions. Birch et al. (2011) collected personal samples during carbon nanofiber production with Sioutas cascade impactors. The impactor stages and the after filter were equipped with quartz-fiber filters to determine the elemental and organic carbon content. Berlinger et al. (2015) collected personal air samples with Sioutas personal cascade impactors among tappers and crane operators in manganese alloy smelters. None of these studies reported any significant challenges with the personal impactors applied for PM sample collection.

As a part of a larger study in metal smelters in Norway, personal aerosol samples were collected by Sioutas cascade impactors and respirable cyclones in parallel in a silicon ( $\mathrm{Si}$ ) metal smelter to investigate the different PM fractions. The present paper describes the challenges with the applied personal cascade impactor samplers in this environment, discusses the possible reasons for the malfunction of the impactors and presents selected results largely unaffected from error.

\section{MATERIALS AND METHODS}

\subsection{Sampling Site and Subjects}

Personal air samples among 25 furnace workers and nine stationary samples at one location were collected in a Si metal smelter in Norway in autumn 2013 and in spring 2016, respectively. The plant has two smelting furnaces producing metallurgical Si. The main work tasks of the furnace workers were to control the tapping process from the furnace and to operate the cranes during casting of liquid Si.

\subsection{Aerosol Sampling}

The sampling strategy followed more or less the same procedure as reported in Berlinger et al. (2015) where each worker carried three samplers. A Sioutas cascade impactor with four impaction stages (SKC, Eighty Four, PA, USA) ran in parallel with a respirable cyclone (JS Holdings, Stevenage, UK) collecting the respirable PM fraction (parallel respirable fraction) for 2 to 3 hours. A second respirable cyclone was used to collect full-shift (approx. 8 hours) air samples in the breathing zone of workers (full-shift respirable fraction).

The impactor and the cyclones both are inertial particle collectors, but differ in the flow geometry and therefore used inertial forces. While an impactor relies on the particle momentum to separate the particle from the gas flow, in a cyclone the centrifugal force is used. For an overview, refer to Marple et al. (2011).

The Sioutas cascade impactor was operated at a flow rate of $9 \mathrm{~L} \mathrm{~min}^{-1}$ Particles are separated on the impactor stages from the top to the bottom in the following aerodynamic particle diameter ranges (in $\mu \mathrm{m}$ ): 10-2.5, 2.5-1.0, 1.0-0.5, 0.5-0.25. Particles on the four impaction stages are collected on 25-mm polytetrafluoroethylene (PTFE) filter substrates with $0.5 \mu \mathrm{m}$ pore-size (Pall Corporation, Port Washington, NY, USA), whereas particles below the $0.25 \mu \mathrm{m}$ cut-point of the last stage are collected on a $2.0 \mu \mathrm{m}$ pore-size 37-mm PTFE after-filter (SKC, Eighty Four, PA, USA). More information on the Sioutas cascade impactors have been published (Misra et al., 2002; Singh et al., 2003).

The 37-mm plastic cassettes in the cyclones were equipped with $5.0 \mu \mathrm{m}$ pore-size PVC membrane filters (Millipore Corp., Billerica, MA, USA). In-house built PS103 personal sampling pumps (National Institute of Occupational Health, Oslo, Norway) were used to maintain the flow rate of $2.2 \mathrm{~L} \mathrm{~min}^{-1}$ required for the respirable cyclones.

For the impactors, Leland Legacy model high flow personal sampling pumps (SKC, Eighty Four, PA, USA) were applied to maintain the $9 \mathrm{~L} \mathrm{~min}^{-1}$ flow. Because of the pressure drop limitations of these pumps mentioned in our earlier publication (Berlinger et al., 2015), none of the pumps was able to operate more than 2-3 hours in the Si metal smelter. The sampling for the impactors and cyclones running in parallel was therefore intentionally stopped after 2-3 hours sampling time.

After processing the aerosol samples from the first sampling campaign and discovering the 


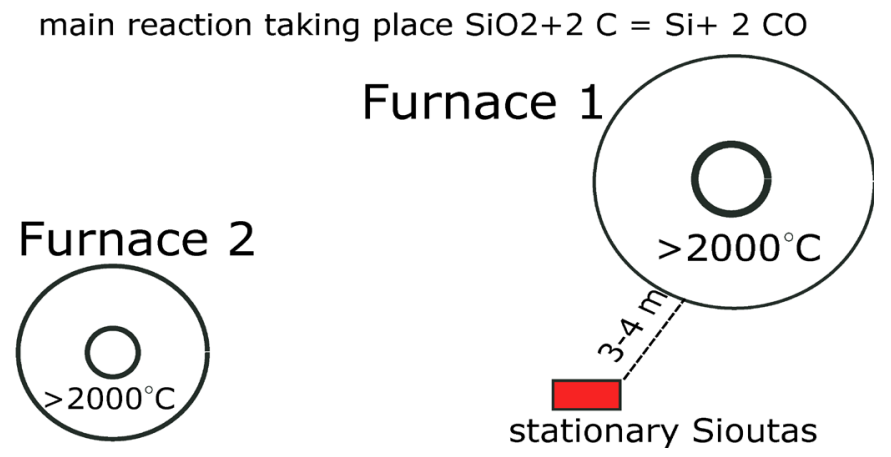

Fig. 1. Sketch showing the location of the stationary Sioutas impactors relative to the furnaces.

malfunction of the impactors, in a second campaign nine new air samples were collected with the Sioutas personal cascade impactors using stationary sampling at a location 3-4 meters from furnace 1 (Fig. 1). The sampling time varied between 3 and 77 minutes depending on the expected particle concentrations in the workplace air.

Submicron particles was collected directly onto copper TEM grids (Holey Carbon film on Copper H7, Agar Scientific, Stansted, UK) with an electrostatic sampler ESPnano model 100 (ESPnano Inc., Spokane, WA, USA). Sampling times were suggested by the producer for various particle concentrations. Based on these recommendations, the sampling times were in the range of 5$100 \mathrm{~s}$.

\subsection{Analysis}

The aerosol particulate masses collected on the filter substrates and the filters in the first sampling campaign were determined gravimetrically by a Sartorius Micro model MC5 balance (Sartorius AG, Göttingen, Germany). The weighing room, dedicated to low filter mass measurements, had constant temperature $\left(20 \pm 1^{\circ} \mathrm{C}\right)$ and relative humidity $(40 \pm 2 \%)$ conditions. The balances were calibrated daily. Certified reference masses (19.989 \pm 0.030 and $49.953 \pm 0.040 \mathrm{mg}$ ) were weighed to assess the accuracy and precision of the mass measurements. The mass detection limits (DLs) calculated as 3 times standard deviation of all field blanks were below $0.01 \mathrm{mg}$ for the different filter types used in the study.

In order to quantify the magnitude of wall deposition in the 9 stationary samples collected during the second sampling campaign, the inner surfaces of each impactor part (the after-filter housing, the top and the bottom of the accelerator plates and the collector plates) were wiped with small pieces $\left(4-6 \mathrm{~cm}^{2}\right.$ ) of Kleenex (Kimberly-Clark Europe Ltd., Reigate, Surrey, UK) to collect the deposited particles on the inner walls of the impactor for further analysis. In order to dissolve the particles mainly consisting of amorphous silica, the impactor substrates, the after-filters and the Kleenex pieces were placed to $15 \mathrm{~mL}$ polypropylene tubes (Sarstedt AG, Numbrecht, Germany), and $2.0 \mathrm{~mL} 40 \%$ hydrofluoric acid (Sigma-Aldrich, St. Louis, MO, USA) and $100 \mu \mathrm{L}$ of an internal standard solution containing $140 \mu \mathrm{g} \mathrm{mL}^{-1}$ of beryllium (Be) were added to them. After a day, the samples were diluted to $14 \mathrm{~mL}$ with deionised water $(18.2 \mathrm{M} \Omega \mathrm{cm}$, Millipore Corp., Billerica, MA, USA). Filter and Kleenex blank samples were made by preparing unexposed filters and Kleenex pieces by the same procedure. The Si concentration of the solutions was determined by a Perkin Elmer Optima 7300 (Perkin Elmer Inc., Waltham, USA) inductively coupled plasma optical emission spectrometer (ICP-OES). The detection limit for Si was 5 and $7 \mu \mathrm{g}$ in case of filter and Kleenex, respectively. For quality control of the determinations, small portions (0.9-7.9 mg) of amorphous $\mathrm{SiO}_{2}(99 \%$, average particle size $80 \mathrm{~nm}$ ) supplied by nanoAmor (Nanostructured and Amorphous Materials Inc., Houston, TX, USA) were used. The recoveries for these small portions of amorphous $\mathrm{SiO}_{2}$ were between 78 and $91 \%$, which was sufficient for the purpose of the determinations.

The TEM grids were analysed with a JEOL JEM 2100F transmission electron microscope (TEM) operated at $200 \mathrm{kV}$ acceleration voltage and a FEI Quanta 400F ESEM scanning electron microscope (SEM) operated at $12.5 \mathrm{kV}$. Both instruments are equipped with Energy Dispersive $X$-ray detector (EDX), which was applied in spot mode on selected particles. Samples were imaged in TEM and SEM. Only SEM images are used for the determination of the size of agglomerates, 
because the largest agglomerate sizes were larger than the field of view in TEM. TEM images are used for particle internal structure determination. The images in SEM were recorded with a resolution of $30 \mathrm{~nm} /$ pixel using secondary electrons (morphological contrast). Image analysis was performed with FIJI/ImageJ (Schneider et al., 2012) using the internal particle sizing algorithm.

\subsection{Calculations and Statistics}

Impactor data was used to calculate the concentrations of the respirable PM fraction as it was described in our previous article (Berlinger et al., 2015) in order to compare these data with the concentrations measured in the respirable cyclones.

Statistical calculations were performed in IBM ${ }^{\circledR}$ SPSS $^{\circledR}$ statistical programme, version 21.0 (SPSS Inc, Chicago, Illinois, United States). Logarithmic transformation was applied for concentrations. Two groups of workers (e.g., furnace 1 and 2) and two dependent variables (e.g., two parallel samples) were compared by performing independent sample and paired sample t-tests. A twotailed $p$-value $<0.05$ was considered as the level of statistical significance.

\section{RESULTS}

\subsection{Challenge with the Impactors}

Concentrations of the different PM size fractions collected by the personal impactors were compared to concentrations of the respirable fraction collected in parallel by the personal respirable cyclones as the first step of the evaluation. The correlations between the concentrations of the five fractions collected in the Sioutas impactor and the concentration of the parallel respirable fraction were low with the exception of the $<0.25 \mu \mathrm{m}$ size fraction (Figs. 2 and 3 ). The respirable fraction calculated from the impactor data was on average $40 \%$ lower than the respirable fraction collected in parallel by the respirable cyclones (Fig. 4). This finding can only be explained by the malfunctioning of one or both sampling devices. Another finding was that the proportion of the $<0.25 \mu \mathrm{m}$ fraction related to the total mass collected by the impactor was increasing with the increasing respirable PM concentrations (Fig. 5).

\subsection{Quantification of Wall Deposition in the Sioutas Cascade Impactors}

It was assumed that most of the PM in the sampled workplace air existed in form of amorphous $\mathrm{SiO}_{2}$. This assumption could be verified by measuring the amount of $\mathrm{Si}$ on the filter samples from the second sampling campaign, calculating the amount of amorphous $\mathrm{SiO}_{2}$ based on the quantity

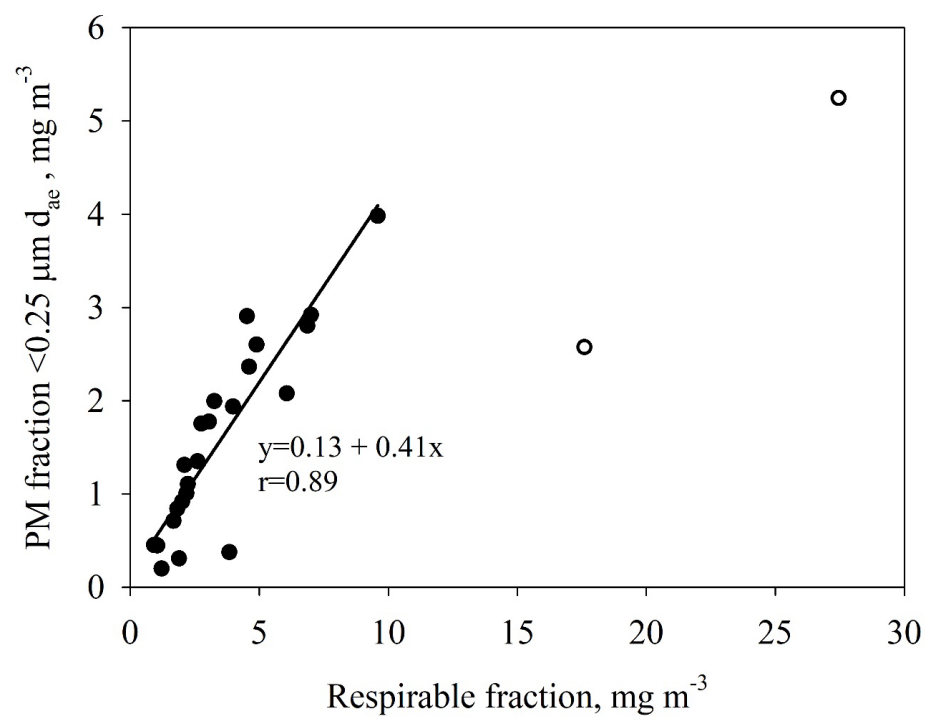

Fig. 2. The association between the concentrations of the PM fraction $<0.25 \mu \mathrm{m} \mathrm{d}_{\mathrm{ae}}$ and the concentrations of respirable fraction measured in the Si metal smelter ( $n=25$, personal sampling). The two values represented by open circles are considered to be outliers. 


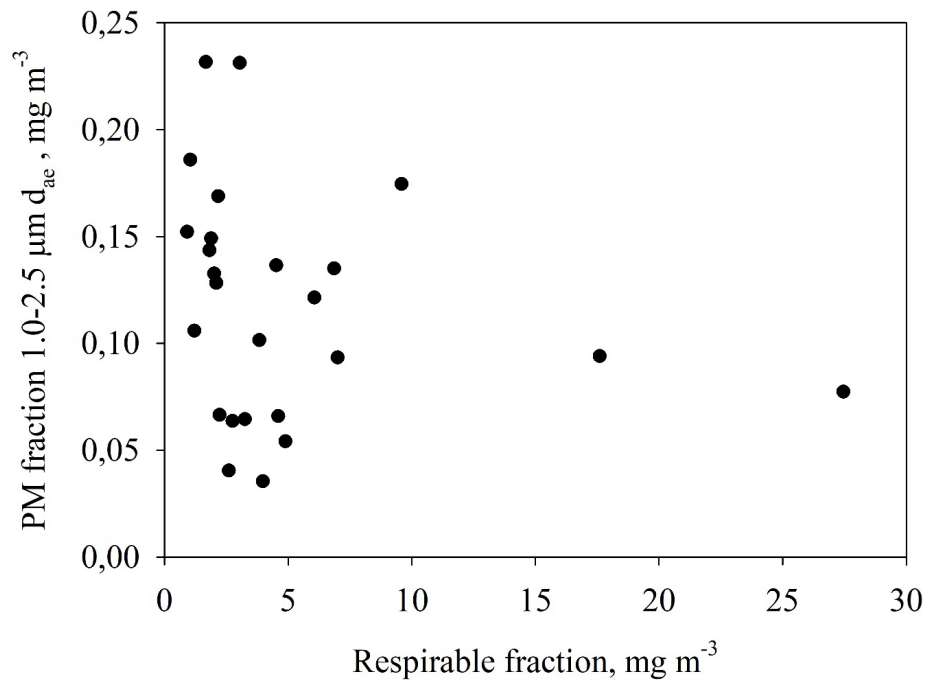

Fig. 3. The association between the concentrations of the PM fraction 1.0-2.5 $\mu \mathrm{m} \mathrm{d}_{\mathrm{ae}}$ and the concentrations of respirable fraction measured in the Si metal smelter ( $n=25$, personal sampling).

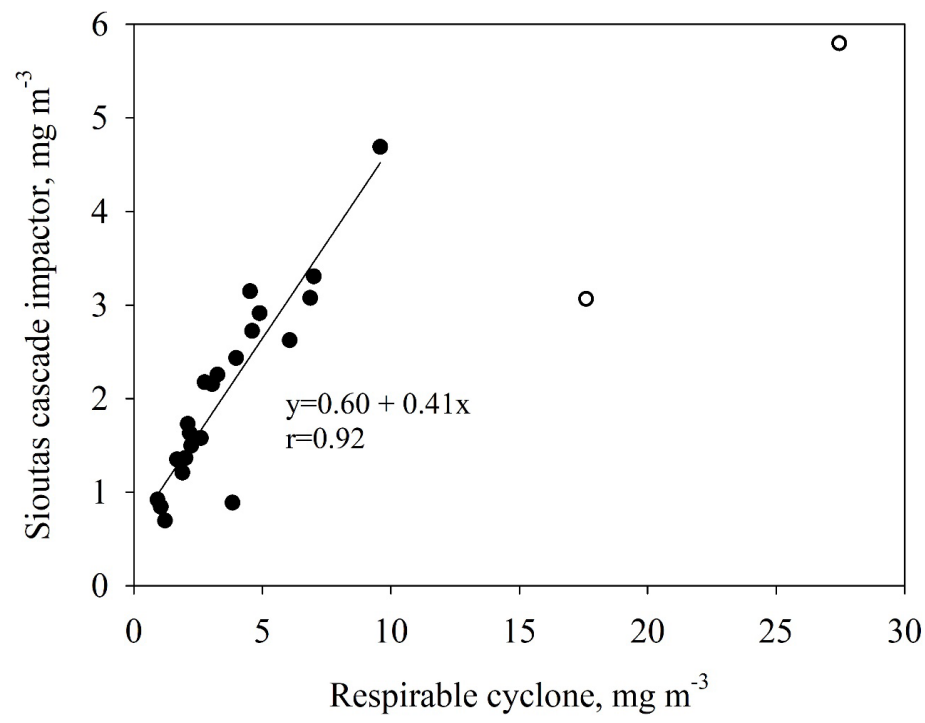

Fig. 4. The association between the concentrations of the respirable fractions calculated from impactor data and measured by respirable cyclones in the Si metal smelter $(n=25$, personal sampling). The two values represented by open circles are considered to be outliers.

of $\mathrm{Si}$ and comparing the amount of $\mathrm{SiO}_{2}$ to the amount of $\mathrm{PM}$ weighed on the filters. These results are summarised in Table 1.

The amount of the deposited amorphous $\mathrm{SiO}_{2}$ (calculated from $\mathrm{Si}$ ) on each filter substrate was compared to the amounts of the $\mathrm{SiO}_{2}$ deposited on the accelerator plate and the collector plate above and under the respective filter substrate. The deposited amounts of $\mathrm{SiO}_{2}$ on the top and the bottom of the accelerator plates were handled separately in these comparisons. The deposited amount of $\mathrm{SiO}_{2}$ on the inner surface of the after-filter housing was compared to the amount of $\mathrm{SiO}_{2}$ deposited on the after-filter. The results (given in percentages) are summarised in Table 2 and visualized with box plots on Fig. 6. It should be mentioned that the concentration of PM during the second air sampling varied over a larger range than during the first sampling campaign. The ranges for the concentration of respirable PM were $0.92-27.5 \mathrm{mg} \mathrm{m}^{-3}$ and $2.7-83.4 \mathrm{mg} \mathrm{m}^{-3}$ during the first and second air sampling, respectively. The relative wall losses seemed to be higher by higher respirable PM concentrations, but clear tendency for the concentration dependence could not be revealed (results not tabulated or plotted). 


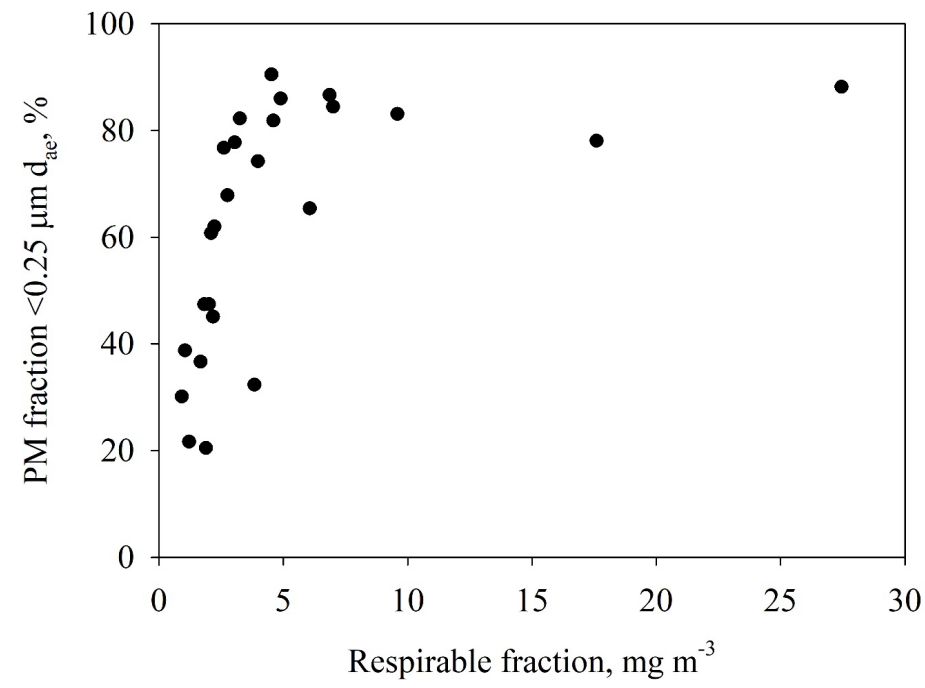

Fig. 5. The proportions of the $<0.25 \mu \mathrm{m} \mathrm{d}_{\mathrm{ae}} \mathrm{PM}$ fraction related to the total PM mass collected by the impactor vs. the concentrations of the respirable fraction ( $n=25$, personal sampling).

Table 1. Mass of particulate matter (PM) on the filter substrates in different impactor stages of the Sioutas cascade impactor and the relative amounts of amorphous silica $\left(\mathrm{SiO}_{2}\right)$ compared to $\mathrm{PM}(\mathrm{n}=9)$.

\begin{tabular}{|c|c|c|c|c|c|c|c|c|}
\hline & \multicolumn{4}{|c|}{$\mathrm{PM}$ in $\mu \mathrm{g}$} & \multicolumn{4}{|c|}{$\mathrm{SiO}_{2}$ in $\%$ of $\mathrm{PM}$} \\
\hline & $\mathrm{AM}^{\mathrm{a}}$ & Median & Min. & Max. & AM & Median & Min. & Max. \\
\hline$<0.25 \mu \mathrm{m}$ & 3.023 & 2.492 & 0.522 & 8.191 & 89 & 90 & 74 & 95 \\
\hline $0.25-0.5 \mu \mathrm{m}$ & 0.134 & 0.127 & 0.081 & 0.239 & 87 & 89 & 62 & 99 \\
\hline $0.5-1.0 \mu \mathrm{m}$ & 0.079 & 0.038 & 0.013 & 0.258 & 85 & 89 & 56 & 98 \\
\hline $1.0-2.5 \mu \mathrm{m}$ & 0.081 & 0.049 & 0.010 & 0.339 & 91 & 94 & 79 & 98 \\
\hline $2.5-10 \mu \mathrm{m}$ & 0.145 & 0.079 & 0.012 & 0.651 & 87 & 89 & 75 & 97 \\
\hline
\end{tabular}

arithmetic mean.

Table 2. Deposited amount of amorphous silica $\left(\mathrm{SiO}_{2}\right)$ on the inner surfaces (in \%) of the different impactor parts (A-D) in the Sioutas cascade impactor (the amount of $\mathrm{SiO}_{2}$ on the respective filter is $100 \% ; n=9$ ).

\begin{tabular}{lllll}
\hline & AM $^{\mathrm{a}}$ & Median & Min. & Max. \\
\hline AP $^{\mathrm{b}} \mathbf{A}^{\mathrm{c}}$ top & 104 & 103 & 40 & 215 \\
AP A bottom & 96 & 90 & 15 & 189 \\
CP $^{\mathrm{d}}$ A & 174 & 143 & 33 & 557 \\
AP B top & 144 & 56 & 43 & 367 \\
AP B bottom & 121 & 83 & 73 & 205 \\
CP B & 202 & 130 & 24 & 561 \\
AP C top & 133 & 57 & 29 & 521 \\
AP C bottom & 108 & 74 & 32 & 309 \\
CP C & 402 & 122 & 46 & 1952 \\
AP D top & 55 & 49 & 16 & 120 \\
AP D bottom & 123 & 114 & 16 & 340 \\
CP D & 479 & 431 & 36 & 1412 \\
After-filter housing & 4 & 3 & 2 & 8 \\
\hline
\end{tabular}

a Arithmetic mean.

${ }^{b}$ Accelerator plate.

${ }^{\mathrm{c}}$ Part of the impactor collecting PM with $2.5 \mu \mathrm{m}<\mathrm{d}_{\mathrm{ae}}<10 \mu \mathrm{m}$.

${ }^{\mathrm{d}}$ Collector plate.

e Part of the impactor collecting PM with $1.0 \mu \mathrm{m}<\mathrm{d}_{\mathrm{ae}}<2.5 \mu \mathrm{m}$.

${ }^{f}$ Part of the impactor collecting PM with $0.5 \mu \mathrm{m}<\mathrm{d}_{\mathrm{ae}}<1.0 \mu \mathrm{m}$.

g Part of the impactor collecting PM with $0.25 \mu \mathrm{m}<\mathrm{d}_{\mathrm{ae}}<0.5 \mu \mathrm{m}$.

${ }^{h}$ The deposited amount of $\mathrm{SiO}_{2}$ on the inner wall was compared with the amount of $\mathrm{SiO}_{2}$ on the after-filter $\left(d_{a e}<0.25 \mu \mathrm{m}\right)$. 


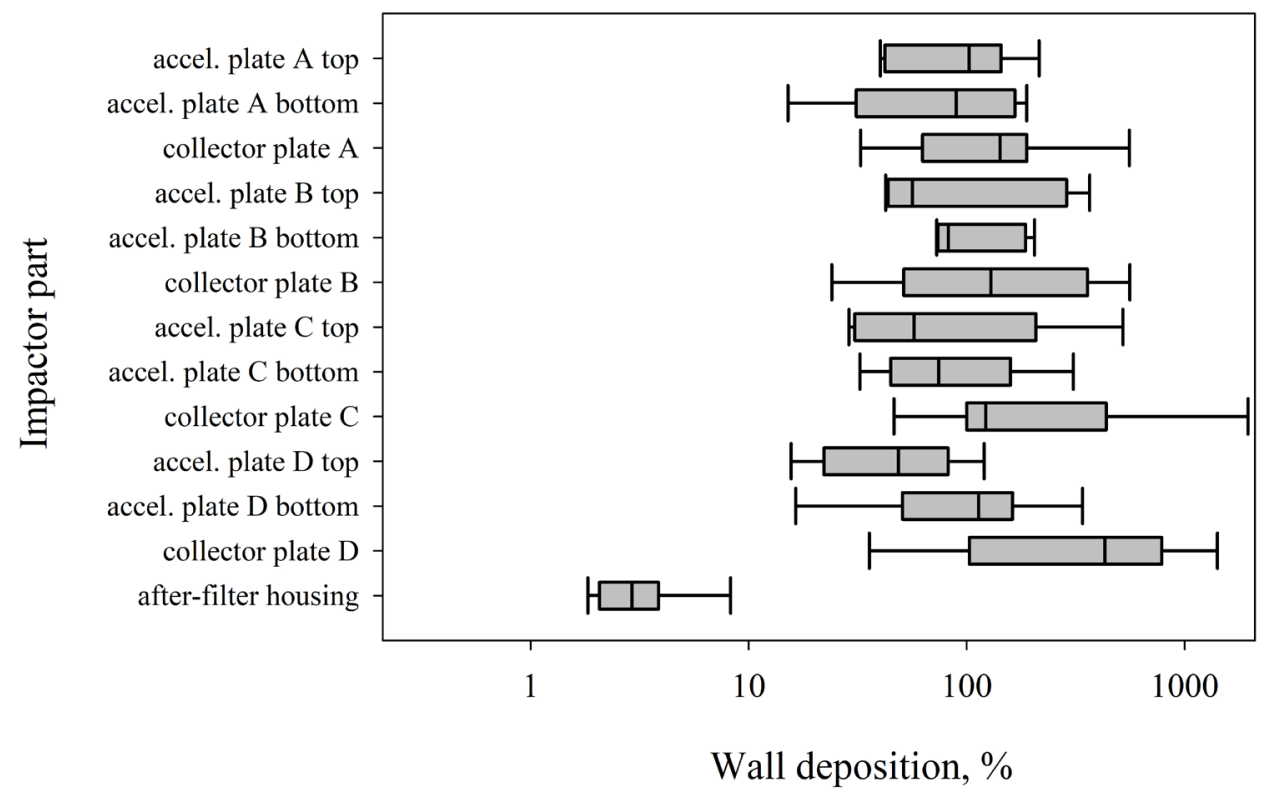

Fig 6. Deposited amount of amorphous silica $\left(\mathrm{SiO}_{2}\right)$ on the inner surfaces of the different impactor parts $(A-D)$ in the Sioutas cascade impactor (compared to the amount of $\mathrm{SiO}_{2}$ on the respective filter; $n=9)$.

\subsection{Particle Characterisation by Electron Microscopy}

The $\mathrm{SiO}_{2}$ particles had a chain structure and were composed of primary spheres with a strongly variable diameter ranging from approximately $10 \mathrm{~nm}$ to $500 \mathrm{~nm}$ in the same aggregate (Fig. 7). The aggregate shape is in principle similar to soot particles (Weinbruch et al., 2018), but the primary sphere diameter is considerably more variable for the $\mathrm{SiO}_{2}$ chains. TEM images show that the smallest particles are not spheres any more (Fig. 8). On nanometer scale, a structured surface can be observed, which increases the surface area of the particles. It cannot be excluded, however, that the roughness of the surface is partly caused by the electron beam (beam damage). Due to their extreme fractal structure, the aerodynamic size of the particles is considerably smaller than their geometrical size (Meakin and Donn, 1988; Van Gulijk et al., 2004).

\subsection{Workplace Particulate Matter Concentrations}

As wall deposition may have caused substantial sample loss in the upper impactor stages, concentrations only of the finest PM fraction $(<0.25 \mu \mathrm{m})$, which was most probably not affected by wall deposition, and the PM fractions measured by the respirable cyclones are considered to be correct and given in Table 3. The correlation between the concentrations of the parallel and the full-shift respirable fractions was relatively low $(r=0.40)$ most probably due to the shorter (2-3 hours) sampling periods of the parallel respirable fraction. The measured concentrations of the parallel and full-shift respirable fractions and the concentrations of the $<0.25 \mu \mathrm{m}$ PM fraction were statistically significantly different $(p<0.01)$ at the two furnaces in the Si metal smelter. Workers at furnace $2\left(\mathrm{GM}_{\text {parallel resp }}=4.94 \mathrm{mg} \mathrm{m}^{-3}, \mathrm{GM}_{\text {full-shift resp }}=5.23 \mathrm{mg} \mathrm{m}^{-3}, \mathrm{GM}_{<0.25 \mu \mathrm{m}}=2.14 \mathrm{mg} \mathrm{m}^{-3}\right)$ were exposed to more than twice the concentrations of PM compared to workers at furnace 1 $\left(\mathrm{GM}_{\text {parallel } \text { resp }}=2.12 \mathrm{mg} \mathrm{m}^{-3}, \mathrm{GM}_{\text {full-shift resp }}=2.46 \mathrm{mg} \mathrm{m}^{-3}, \mathrm{GM}_{<0.25 \mu \mathrm{m}}=0.71 \mathrm{mg} \mathrm{m}^{-3}\right)$.

\section{DISCUSSION}

\subsection{Challenge with the Impactors, Wall Losses}

The following factors were considered as explanations of the observations regarding Sioutas cascade impactors in the Si metal smelter: particle bouncing and blow off, high particle mass loading, impact fragmentation of the particle agglomerates, wall deposition of the particles, and the effect of high PM concentration on the impactor performance. 

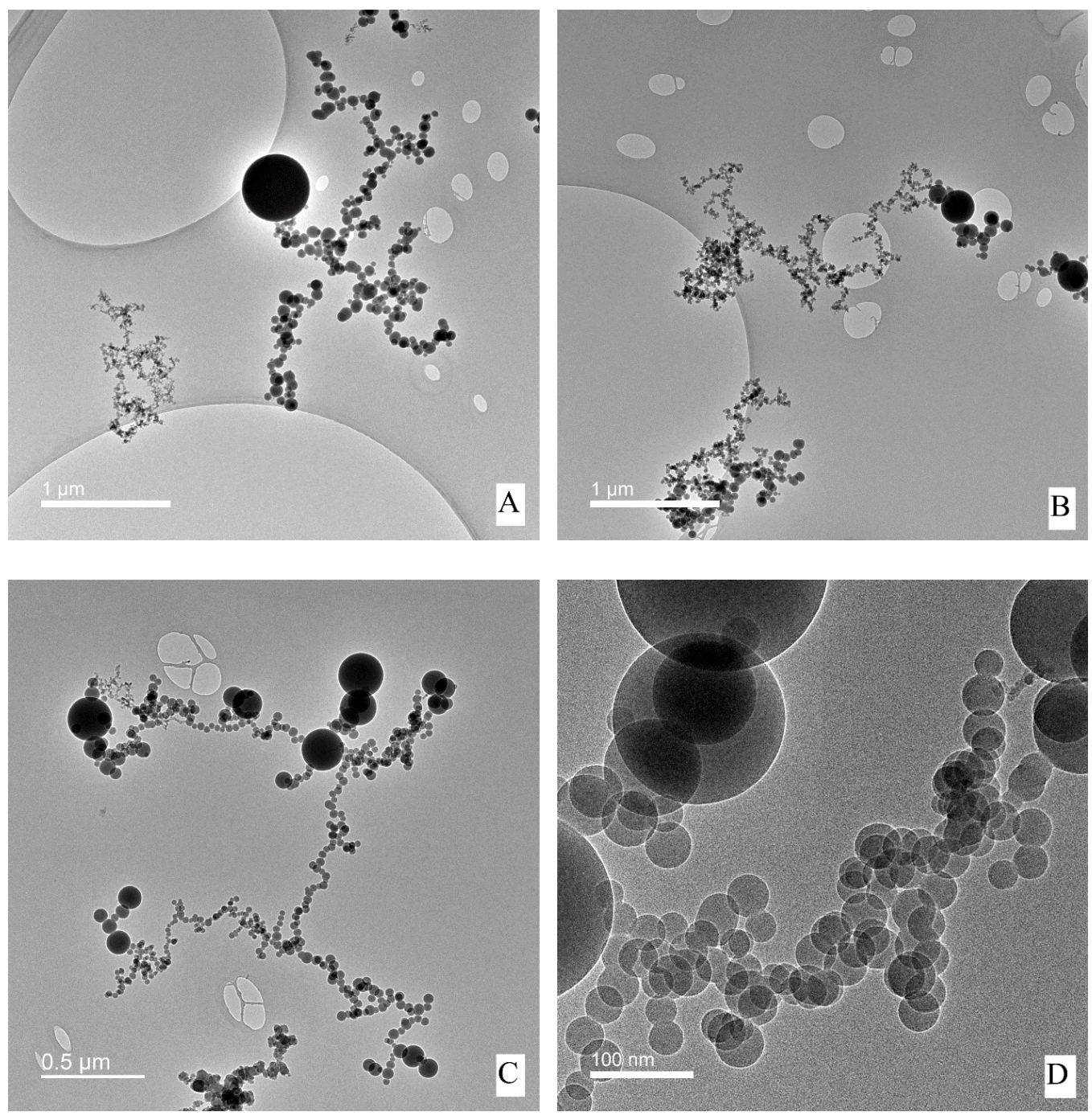

Fig. 7. Chain-like agglomerates of $\mathrm{SiO}_{2}$ particles sampled on TEM grids in a silicon metal smelter, composed of primary spheres with a strongly variable diameter ranging from approximately 10 $\mathrm{nm}$ to $500 \mathrm{~nm}$ in the same aggregate.
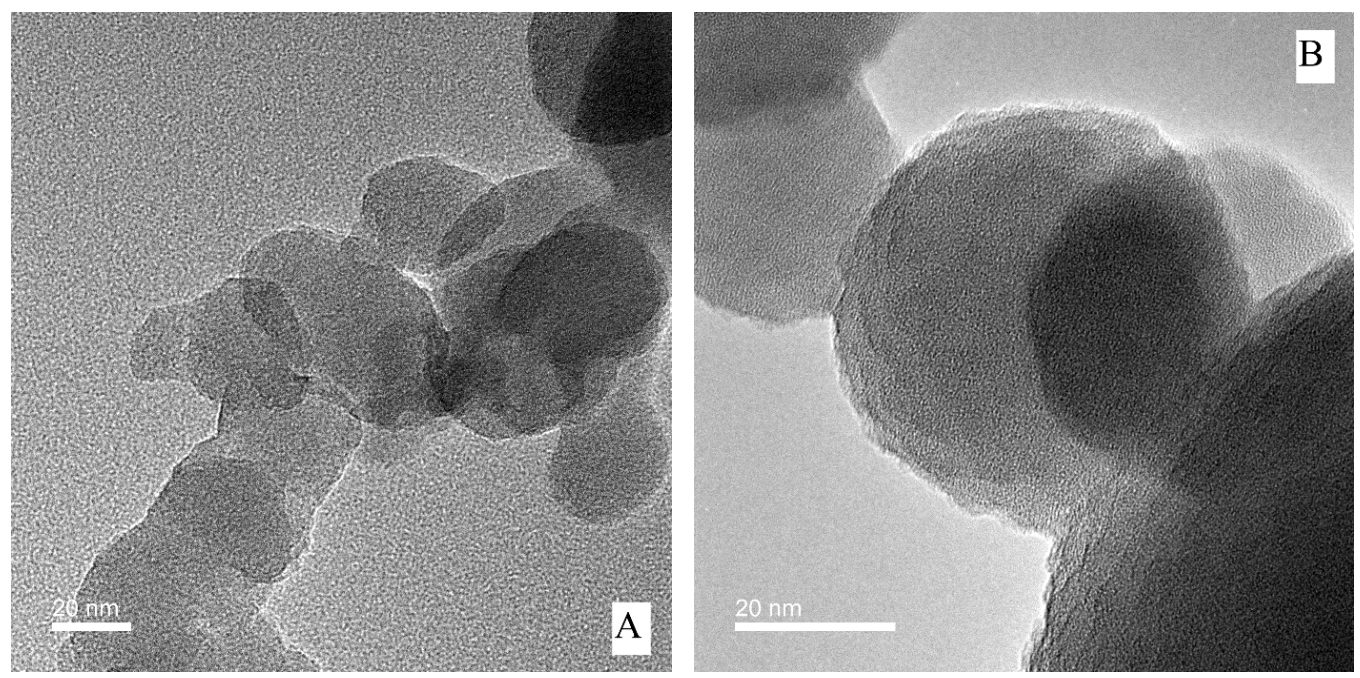

Fig. 8. Nanostructure of agglomerated $\mathrm{SiO}_{2}$ particles sampled on TEM grids in a silicon metal smelter. 
Table 3. Concentrations (in $\mathrm{mg} \mathrm{m}^{-3}$ ) of selected PM fractions measured in the Si metal smelter (personal sampling).

\begin{tabular}{lllllllll}
\hline & \multicolumn{9}{c}{ Percentiles } \\
\cline { 2 - 9 } & $\mathrm{N}^{\mathrm{a}}$ & $\mathrm{AM}^{\mathrm{b}}$ & Min. & Max. & 10 & 90 & $\mathrm{GM}^{\mathrm{c}}$ & $\mathrm{GSD}^{\mathrm{d}}$ \\
\hline Parallel respirable fraction $^{\mathrm{e}}$ & 25 & 5.01 & 0.916 & 27.5 & 1.14 & 12.8 & 3.41 & 2.28 \\
Full-shift respirable fraction $^{\mathrm{f}}$ & $22^{\mathrm{g}}$ & 4.24 & 1.04 & 12.8 & 1.86 & 6.09 & 3.71 & 1.71 \\
$<0.25 \mu \mathrm{m}$ (in Sioutas impactor) & 25 & 1.76 & 0.199 & 5.25 & 0.348 & 3.35 & 1.32 & 2.34 \\
\hline
\end{tabular}

${ }^{a}$ Number of measurements.

${ }^{\mathrm{b}}$ Arithmetic mean.

${ }^{\mathrm{C}}$ Geometric mean.

${ }^{\mathrm{d}}$ Geometric standard deviation.

${ }^{\text {e }}$ Respirable PM fraction sampled with the respirable cyclone ran in parallel with the impactor.

${ }^{f}$ Respirable PM fraction sampled with the respirable cyclone collecting the full-shift sample.

g 3 measurements were excluded due to unexpected stop of the sampling pump during sampling.

The respirable PM concentration was sometimes high (up to $27.5 \mathrm{mg} \mathrm{m}^{-3}$ in the personal samples), but even the highest concentration was much lower than the concentrations which have been suggested to influence the separation in the impactor (Her and Kim, 1991). Particle bouncing and blow off as well as the effect of high particle mass loading in the Sioutas cascade impactor were examined thoroughly by Misra et al. (2002). Their laboratory loading tests of the $0.25-0.5 \mu \mathrm{m}$ stage demonstrated that particle bounce and re-entrainment, which would have been manifested by detectable decrease in collection efficiency measured for any particle sizes, do not occur for loadings at least as high as $3.16 \mathrm{mg}$ at this stage. The highest loading of $0.73 \mathrm{mg}$ on the $0.25-0.5 \mu \mathrm{m}$ stage in our study was much lower than this amount. Proportions of the finest fraction and the deposited masses on the 0.25-0.5 $\mu \mathrm{m}$ stage were also compared in our study. Higher loading was not associated with higher proportion of the finest fraction. Fragmentation of nanoparticle agglomerates can be achieved by impaction experiments in the low-pressure impactors (Froeschke et al., 2003; Seipenbusch et al., 2007; Ihalainen et al., 2014), though it is not likely to happen in a Sioutas cascade impactor by using a soft substrate filter material like PTFE. In contrast, a carry over to smaller size cut-off stages can be easily explained by the fractal particle structure.

The issues discussed above could explain the increase of the proportion of the finest fraction with increasing PM concentrations, but cannot explain the small amount of PM in the $<10 \mu \mathrm{m}$ fraction compared to the respirable fraction. Misra et al. (2002) found that PM losses in the Sioutas cascade impactor stages caused by inertial deposition on the walls of the acceleration nozzles were quite low $(<10 \%)$, but increased with particle size. Such depositions in the upper stages could be visually observed in the impactors (Fig. 9). Moreover, the fractal structure of the single particles might help in building up structures on the walls with high stickiness due to the roughness provided by the particles itself. Taking into account the information from the literature and our observations, wall deposition in the upper impactor stages was the most likely explanation for the findings, although oversampling by the respirable cyclone could not be excluded. Larger particles (> $10 \mu \mathrm{m} \mathrm{d}_{\mathrm{ae}}$ ) entering the cyclone might be deposited on its walls. If re-suspension from the cyclone wall occurs, these particles might be collected on the cyclone filter. Experimental evidence of this phenomenon, however, cannot be found in the literature.

The relative amount of amorphous $\mathrm{SiO}_{2}$ deposited on the different collector plates of the Sioutas impactor showed an increase from collector plate $A$ to $D$ (decreasing particle sizes). There was some variation in the relative amounts of amorphous $\mathrm{SiO}_{2}$ deposited on the top and the bottom of the collector plates, but the sum of the relative amounts deposited on the collector plates varied over a relatively narrow range (178-265\% of the amount deposited on the respective filter). Studies investigating wall deposition in different impactors found that wall losses tend to decrease with particle size down to a certain size (Cushing et al., 1979; Mitchell et al., 1988; Vaughan, 1989; Rader et al., 1991; Marple et al., 1991; Michaud et al., 1999; Virtanen et al., 2001; Kwon et al., 2003; Demokritu et al., 2004; Stefancova et al., 2011). Some of these studies using impactor types which were able to collect finer particles, revealed that the wall losses might increase in the lower stages collecting fine particles (Marple et al., 1991; Michaud et al., 1999; 

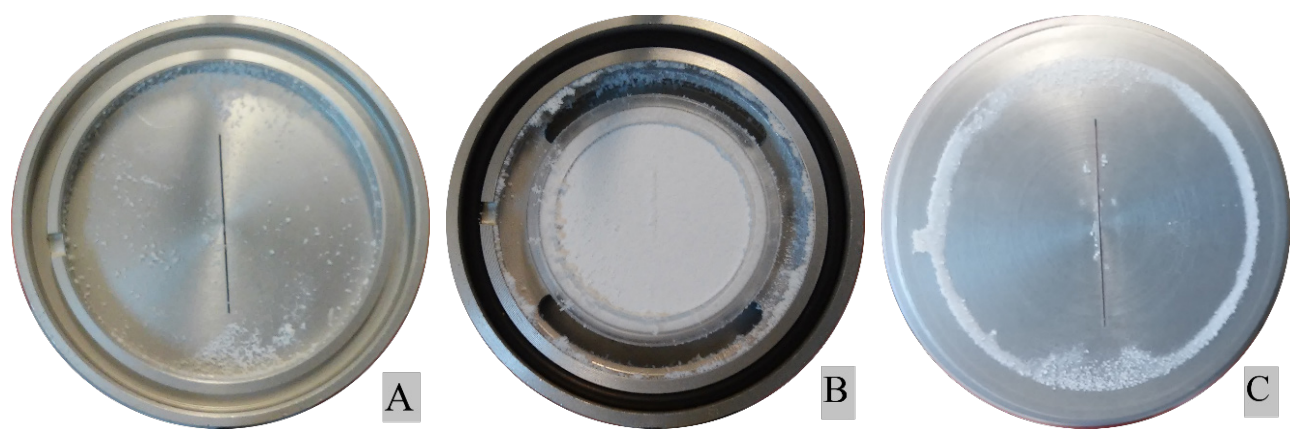

Fig. 9. Deposition of particles on (A) the top of an accelerator plate (B) on a collector plate and (C) on the bottom of an accelerator plate which were part of a Sioutas personal cascade impactor used in a Si metal smelter.

Virtanen et al., 2001; Demokritu et al., 2004; Stefancova et al., 2011). Particles with less than approximately $0.5 \mu \mathrm{m}$ aerodynamic diameter are progressively affected by diffusional forces with decreasing particle size, which will lead to wall deposition of fine particles (Schlesinger, 1995). However, it has to be considered that while the fractal-like particles are aerodynamically small due to their high surface to volume ratio, in terms of mechanical mobility and susceptibility to diffusional movement they remain large, as their mass and total surface are still that of a large particle. Most of the studies, however, used monodisperse aerosols to calibrate and test impactors and found relatively little amount of wall deposits, which therefore are generally considered negligible. There were very few authors who applied polydisperse aerosols (Vaughan, 1989; Durand et al., 2014) for their investigations and they found higher relative wall losses (up to 50\%) than the authors testing the devices with monodisperse aerosols. Still, all these studies were performed in laboratory conditions. There might be papers quantifying wall deposits in impactors used in field studies, but the authors of this paper were not able to locate any.

The main purpose of quantifying the wall deposits was to find out if there was an association between the wall losses and the measured PM concentrations. If such association could be revealed and described, it could be used for the correction of the results from the first sampling campaign when personal samples were collected. The number of samples collected in the second campaign was, however, too few to permit a modelling of an association. One also has to consider that the concentration of PM in a metal smelter is fluctuating over time (Skaugset et al., 2014). Impactors measure average concentration over a period, and if the association between the relative wall losses and the PM concentrations is not linear, average concentrations cannot be used to estimate relative wall losses. The increasing relative amount of the finest PM with increasing respirable PM concentrations (Fig. 5) still indicate that with increasing PM concentrations the wall losses increased in the Sioutas impactors used for personal samplings in the silicon metal smelters. This hypothesis is to a certain extent supported by the quantification of the wall deposits in the stationary used Sioutas impactors, as lower wall losses were usually found by lower respirable PM concentrations.

In the after-filter housings negligible amounts of wall deposited amorphous $\mathrm{SiO}_{2}$ were found, which is one indication that the finest fraction was much less affected by wall losses. A previous study in manganese metal alloy smelters found that particle size distribution was very similar in all personal impactor samples independent on the work task or the workplace (Berlinger et al., 2015). If we assume that the particle size distribution is invariable in the silicon metal smelter too, and consider the high correlation between the $<0.25 \mu \mathrm{m}$ fraction (at least below $10 \mathrm{mg} \mathrm{m}^{-3}$ respirable PM concentration) and the parallel respirable fraction, we might suggest that the finest fraction was not affected by the malfunctioning of the Sioutas impactor and therefore these result can be used. It might also be suggested, that the impactor separation was not impaired by the wall losses, at least not the separation of the finest particles. Moreover, the $<0.25 \mu \mathrm{m}$ fraction is by definition contained in respirable fraction. If these two fractions scale proportionally for different concentrations - as it was described before and shown on Fig. 2-, it means that with a high probability the overall size distribution is not changing, and that selective losses in the after-filter stage are not significant. The finest particles then follow the jet stream all the way 
down to the after-filter, while larger particles are deposited in the respective stages on the filter substrates and the metal surfaces of the accelerator and collector plates. A possible explanation of the latter deposition is that the amorphous $\mathrm{SiO}_{2}$ particles are highly charged and therefore captured by electrostatic forces on the metal surfaces within the Sioutas impactor (de Juan et al., 1997). An elevated charging probability for chain aggregates was described previously (Cheng and Yeh, 1983; Cao et al., 2015).

\subsection{Workplace Particulate Matter Concentrations}

Even if the sampling with the Sioutas cascade impactors was not successful, the authors consider it important to use as many data from the sampling campaign as possible. It is very likely that the finest aerosol fraction in the impactors was not affected by wall deposition or other errors in the impactor performance. There was no evidence for the malfunctioning of the sampling devices collecting respirable PM. The authors therefore decided to accept, publish and use further the concentration results of the finest PM fraction $(<0.25 \mu \mathrm{m})$ and the respirable PM fractions (Bugge et al., 2020)

The relatively low correlation between the parallel and full-shift respirable fractions was most probably due to the different sampling periods, which also suggest the PM concentration can vary considerably during a working day in the Si metal smelter. The statistically significant differences between the PM concentrations measured by the two furnaces might be explained by differences in furnace size, production volume and ventilation conditions.

\section{CONCLUDING REMARKS}

The use of size selective personal samplers can give information that can be used to estimate the pulmonary deposition of particulate matter that has penetrated into the lungs. Such information is important for more accurate estimation of the amount of particulate matter that may cause potential health effects. A better knowledge of particle size distribution is also important to understand health effects from particle exposure in occupational settings. Impactor samplers are useful tools; however, this paper describes limitations that should be acknowledged. Wall deposition will reduce the reliability of the impactors; in the present case, particle charge may add considerably to these losses.

\section{ACKNOWLEDGMENTS}

This study was funded by the Sickness Absence, Work and Health programme of the Norwegian Research Council under Grant 218350. Konrad Kandler is funded by the Deutsche Forschungsgemeinschaft (DFG, German Research Foundation) - 264907654; 416816480. The authors thank Kari Dahl and Ove Aanonsen for their contribution to the air sampling.

\section{REFERENCES}

Bartley, D.L., Vincent, J.H. (2011). Sampling conventions for estimating ultrafine and fine aerosol particle deposition in the human respiratory tract. Ann. Occup. Hyg. 55, 696-709. https://doi.org/10.1093/annhyg/mer037

Berlinger, B., Bugge, M.D., Ulvestad, B., Kjuus, H., Kandler, K., Ellingsen, D.G. (2015). Particle size distribution of workplace aerosols in manganese alloy smelters applying a personal sampling strategy. Environ. Sci. Processes Impacts 17, 2066-2073. https://doi.org/10.1039/c5em00396b

Birch, M.E., Ku, B.K., Evans, D.E., Ruda-Eberenz, T.A. (2011). Exposure and emissions monitoring during carbon nanofiber production-part I: Elemental carbon and iron-soot aerosols. Ann. Occup. Hyg. 55, 1016-1036. https://doi.org/10.1093/annhyg/mer073

Bugge, M.D., Ulvestad, B., Berlinger, B., Stockfelt, L., Olsen, R., Ellingsen, D.G. (2020). Reactive hyperemia and baseline pulse amplitude among smelter workers exposed to fine and ultrafine particles. Int. Arch. Occup. Environ. Health 93, 399-407. https://doi.org/10.1007/s00420-01901491-8 
Cao, L.N.Y., Wang, J., Fissan, H., Pratsinis, S.E., Eggersdorfer, M.L., Pui, D.Y.H. (2015). The capacitance and charge of agglomerated nanoparticles during sintering. J. Aerosol. Sci. 83, 111. https://doi.org/10.1016/j.jaerosci.2015.01.002

Chen, M.R., Tsai, P.J., Chang, C.C, Shih, T.S., Lee, W.J., Liao, P.C. (2007). Particle size distributions of oil mists in workplace atmospheres and their exposure concentrations to workers in a fastener manufacturing industry. J. Hazard. Mater. 146, 393-398. https://doi.org/10.1016/j.jh azmat.2006.12.036

Cheng, Y.S., Yeh, H.C. (1983). Theoretical equilibrium bipolar charge distributions of chain aggregates with uniform spheres. J. Aerosol. Sci. 14, 489-494. https://doi.org/10.1016/00218502(83)90004-6

Cohen, H.J., Powers, B.J. (2000). Particle size characterizations of copper and zinc oxide exposures of employees working in a nonferrous foundry using cascade impactors. Am. Ind. Hyg. Assoc. J. 61, 422-430. https://doi.org/10.1080/15298660008984554

Cushing, K.M., McCain, J.D., Smith, W.B. (1979). Experimental-determination of sizing parameters and wall losses of 5 source-test cascade impactors. Environ. Sci. Technol. 13, 726-731. https://doi.org/10.1021/es60154a019

de Juan, L., Brown, S., Serageldin, K., Davis, N., Rossel, J., Lazanco, J., and Fernandez de la Mora, J. (1997). Electrostatic effects in inertial impactors. J. Aerosol Sci. 28, 1029-1048. https://doi.org/10.1016/S0021-8502(96)00490-9

Demokritou, P., Lee, S.J., Ferguson, S.T., Koutrakis, P. (2004). A compact multistage (cascade) impactor for the characterization of atmospheric' aerosols. J. Aerosol Sci. 35, 281-299. https://doi.org/10.1016/j.jaerosci.2003.09.003

Dufresne, A., Dion, C., Viau, S., Cloutier, Y., Perrault, G. (2009). Beryllium aerosol characteristics in the magnesium and aluminum transformation industry in Quebec: A comparison of four different sampling methodologies. J. Occup. Environ. Hyg. 6, 687-697. https://doi.org/10.108 0/15459620903249828

Durand, T., Bau, S., Morele, Y., Matera, V., Bemer, D., Rousset, D. (2014). Quantification of low pressure impactor wall deposits during zinc nanoparticle sampling. Aerosol Air Qual. Res. 14, 1812-1821. https://doi.org/10.4209/aaqr.2013.10.0304

Froeschke, S., Kohler, S., Weber, A.P., Kasper, G. (2003). Impact fragmentation of nanoparticle agglomerates. J. Aerosol Sci. 34, 275-287. https://doi.org/10.1016/S0021-8502(02)00185-4

Her, J.Y., Kim, S.S. (1991). A numerical study of the effect of a high aerosol concentration on impactor performance. Aerosol Sci. Technol. 14, 157-64. https://doi.org/10.1080/02786829108959479

ICRP (1994). Human Respiratory Tract Model for Radiological Protection. Annals of the ICRP, Pergamon Press, 24, 1-3, Oxford, UK.

Ihalainen, M., Lind, T., Arffman, A., Torvela, T., Jokiniemi, J. (2014). Break-up and bounce of $\mathrm{TiO}_{2}$ agglomerates by impaction. Aerosol Sci. Technol. 48, 31-41. https://doi.org/10.1080/027868 26.2013 .852155

Kwon, S.B., Lim, K.S., Jung, J.S., Bae, G.N., Lee, K.W. (2003). Design and calibration of a 5-stage cascade impactor (K-JIST cascade impactor). J. Aerosol Sci. 34, 289-300. https://doi.org/10.101 6/S0021-8502(02)00177-5

Marple, V.A., Olson, B.A. (2011). Sampling and Measurement Using Inertial, Gravitational, Centrifugal, and Thermal Techniques, in: Kulkarni, P., Baron, P.A., Willeke, K. (Eds.), Aerosol Measurement, John Wiley \& Sons, Inc., Hoboken, NJ, USA, pp. 129-151. https://doi.org/10.10 02/9781118001684.ch8

Marple, V.A., Rubow, K.L., Behm, S.M. (1991). A microorifice uniform deposit impactor (MOUDI): Description, calibration, and use. Aerosol Sci. Technol. 14, 434-446. https://doi.org/10.1080/0 2786829108959504

Meakin, P., Donn, B. (1988). Aerodynamic properties of fractal grains: Implications for the primordial solar nebula. Astrophys. J. Lett. 329, L39-L41. https://doi.org/10.1086/185172

Michaud, D., Picard, P., Baril, M. (1999). A versatile flat-deposit impactor-type aerosol collector Part 2: Calibration and quantitative study. Aerosol. Sci. Technol. 31, 338-349. https://doi.org/ 10.1080/027868299304066

Misra, C., Singh, M., Shen, S., Sioutas, C., Hall, P.A. (2002). Development and evaluation of a personal cascade impactor sampler (PCIS). J. Aerosol Sci. 33, 1027-1047. https://doi.org/10.1 016/S0021-8502(02)00055-1 
Mitchell, J.P., Costa, P.A., Waters, S. (1988). An assessment of an andersen mark-II cascade impactor. J. Aerosol Sci. 19, 213-221. https://doi.org/10.1016/0021-8502(88)90224-8

Nieuwenhuijsen, M.J., Kruize, H., Schenker, M.B. (1998). Exposure to dust and its particle size distribution in California agriculture. Am. Ind. Hyg. Assoc. J. 59, 34-38. https://doi.org/10.108 0/15428119891010316

Rader, D.J., Mondy, L.A., Brockmann, J.E., Lucero, D.A., Rubow, K.L. (1991). Stage response calibration of the mark-III and marple personal cascade impactors. Aerosol Sci. Technol. 14, 365-379. https://doi.org/10.1080/02786829108959499

Schlesinger, R.B. (1995). Deposition and clearance of inhaled particles. In: McClellan, R.O., Henderson, R.F. (Eds.), Concepts in Inhalation Toxicology, 2nd edn., Taylor \& Francis, Washington D.C., USA, p. 191-193. https://doi.org/10.1201/9780367802974

Schneider, C.A., Rasband, W.S., Eliceiri, K.W. (2012). NIH Image to ImageJ: 25 years of image analysis. Nat. Meth. 9, 671-675. https://doi.org/10.1038/nmeth.2089

Seipenbusch, M., Toneva, P., Peukert, W., Weber, A.P. (2007). Impact fragmentation of metal nanoparticle agglomerates. Part. Part. Syst. Char. 24, 193-200. https://doi.org/10.1002/ppsc. 200601089

Singh, M., Misra, C., Sioutas, C. (2003). Field evaluation of a personal cascade impactor sampler (PCIS). Atmos. Environ. 37, 4781-4793. https://doi.org/10.1016/j.atmosenv.2003.08.013

Skaugset, N.P., Berlinger, B., Radziuk, B., Tørring, H., Synes, O., Thomassen, Y. (2014). Visualisation and identification of peak exposure events in aluminium smelter pot rooms using hydrogen fluoride and aerosol real-time portable spectrometers. Environ. Sci. Processes Impacts 16, 1035-1040. https://doi.org/10.1039/c3em00640a

Stefancova, L., Schwarz, J., Mäkelä, T., Hillamo, R., Smolik, J. (2011). Comprehensive characterization of original 10-stage and 7-stage modified berner type impactors. Aerosol Sci. Technol. 45, 88-100. https://doi.org/10.1080/02786826.2010.524266

Van Gulijk, C., Marijnissen, J.C.M., Makkee, M., Moulijn, J.A., Schmidt-Ott, A. (2004). Measuring diesel soot with a scanning mobility particle sizer and an electrical low-pressure impactor: Performance assessment with a model for fractal-like agglomerates. J. Aerosol. Sci. 35, 633655. https://doi.org/10.1016/j.jaerosci.2003.11.004

Vaughan, N.P. (1989). The Andersen impactor - calibration, wall losses and numerical-simulation. J. Aerosol Sci. 20, 67-90. https://doi.org/10.1016/0021-8502(89)90032-3

Virtanen, A., Marjamäki, M., Ristimäki, J., Keskinen, J. (2001). Fine particle losses in electrical lowpressure impactor. J. Aerosol Sci. 32, 389-401. https://doi.org/10.1016/S0021-8502(00)00087-2

Volkwein, J.C., Maynard, A.D., Harper, M. (2011). Workplace Aerosol Measurement, in: Kulkarni, P., Baron, P.A., Willeke, K. (Eds.), Aerosol Measurement, John Wiley \& Sons, Inc., Hoboken, NJ, USA, pp. 571-590. https://doi.org/10.1002/9781118001684.ch25

Weinbruch, S., Benker, N., Kandler, K., Schütze, K., Kling, K., Berlinger, B., Thomassen, Y., Drotikova, T., Kallenborn, R. (2018). Source identification of individual soot agglomerates in Arctic air by transmission electron microscopy. Atmos. Environ. 172, 47-54. https://doi.org/10. 1016/j.atmosenv.2017.10.033 